\title{
Photoelectric Measurement of Fabric Appearance
}

\author{
By Takaharu Suwa, Minoru Uno and Akira Shiomi \\ Faculty of Industrial Arts, Kyoto Technical University, Kyoto. \\ Based on Journal of the Textile Machinery Society of Japan, Transactions, Vol. 18, No.9, T 600- \\ 606 (1964)
}

\begin{abstract}
Some valuable data as an aid in building a cloth inspecting machine have been obtained by optically evaluating the apparent imperfections (look) of fabrics. A device made for the evaluation was designed to cast a slender light beam vertically on a fabric and measure the quantity of reflecting or passing light.

Imperfections in dyeing or fiber gloss were fully detected by reflecting light. Defects due to structural distorsions were revealed by passing light. The ranking of cloth defects observed with the naked eye agreed well with the ranking of the irregularity observed by reflecting light.
\end{abstract}

\section{Introduction}

The irregularity of appearance of woven fabrics is an important factor in determining their quality, especially the quality of those used for garments. Yet there are hardly any published works on the subject, except, perhaps, those by Catling[1] and Schulze[2]. Catling studied the influence of the sinusoidal irregularity of yarns on fabric appearance. Schulze looked into various causes of fabric streakiness.

Fabric appearance is, at present, evaluated with the naked eye, with the result that personal errors of the evaluator and the influence of the environment in which the evaluation is made are unavoidable. Evaluation with the naked eye lacks reproducibility and objectivity. Yet most cloth inspecting machines rely on human eyes for appearance evaluation. A new inspecting machine which insures objective validity is unquestionably needed.

A new machine experimentally made by the Tôyo Kiryo Co., of Japan, observes with phototransistors both light reflecting on woven fabrics and light penetrating them. Some other inspection methods have been tried by using a contact probe to detect the irregularity of fabric thickness $[3]$, or by projecting the fabric image on frosted glass[4].

Fester and Küppers[5] reported on a method to measure the irregularity of woven fabrics on a "Chromoscan" tester which uses the intensity difference between reflections produced by the measuring light and standard light.

This article evaluates the irregularity of fabric appearance by light reflecting on a running cloth and light penetrating it. The object is to look into the character of the irregularity of fabric appearance and obtain basic data on automatic inspection of cloth.

\section{Experimental Apparatus}

A general view of the apparatus used in our experiment is shown in Fig. 1, where 1 is the light source; 2 , the main body; 3 , the electricity source; 4 , the electric stabilizer; 5 , the amplifier; and 6 , the recording unit. By loosening fastners 7 of the main body, the upper covers are opened around hinges 8 . The apparatus consists of three parts: mechanical, optical and electrical.

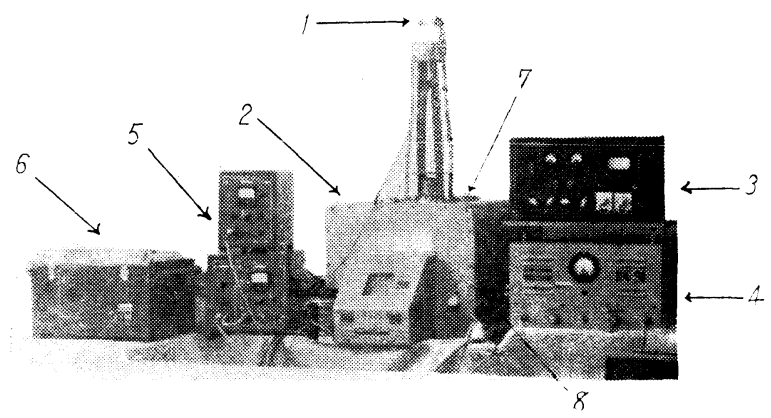

Fig. 1 General view of apparatus

2-1 Mechanical Part

Fig. 2 shows the mechanical system. Fabric specimen $\mathrm{E}, 4 \mathrm{~cm}$ in width, is held by rollers $F_{1}, F_{1^{\prime}}$ and $F_{2}, F_{2^{\prime}}$ and carried in the direction shown by the arrow. 


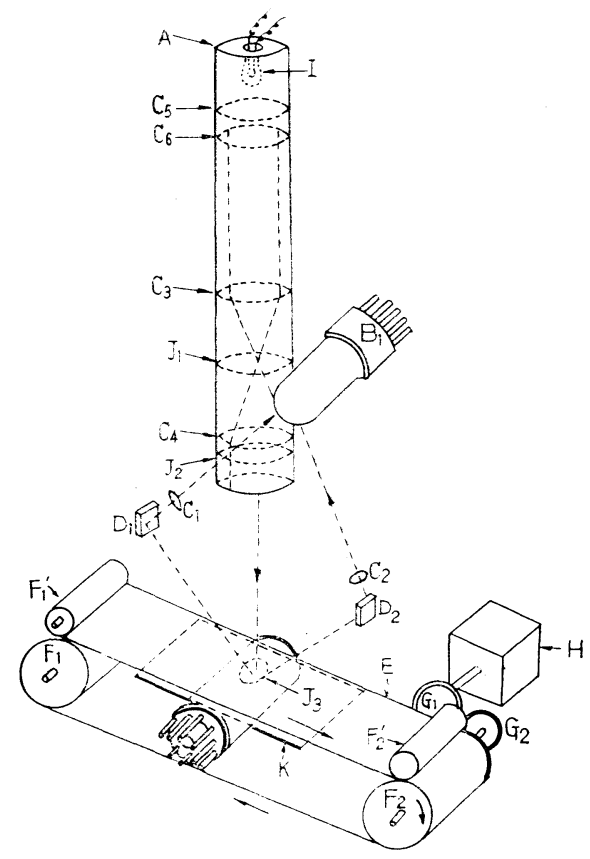

Fig. 2 General build of apparatus

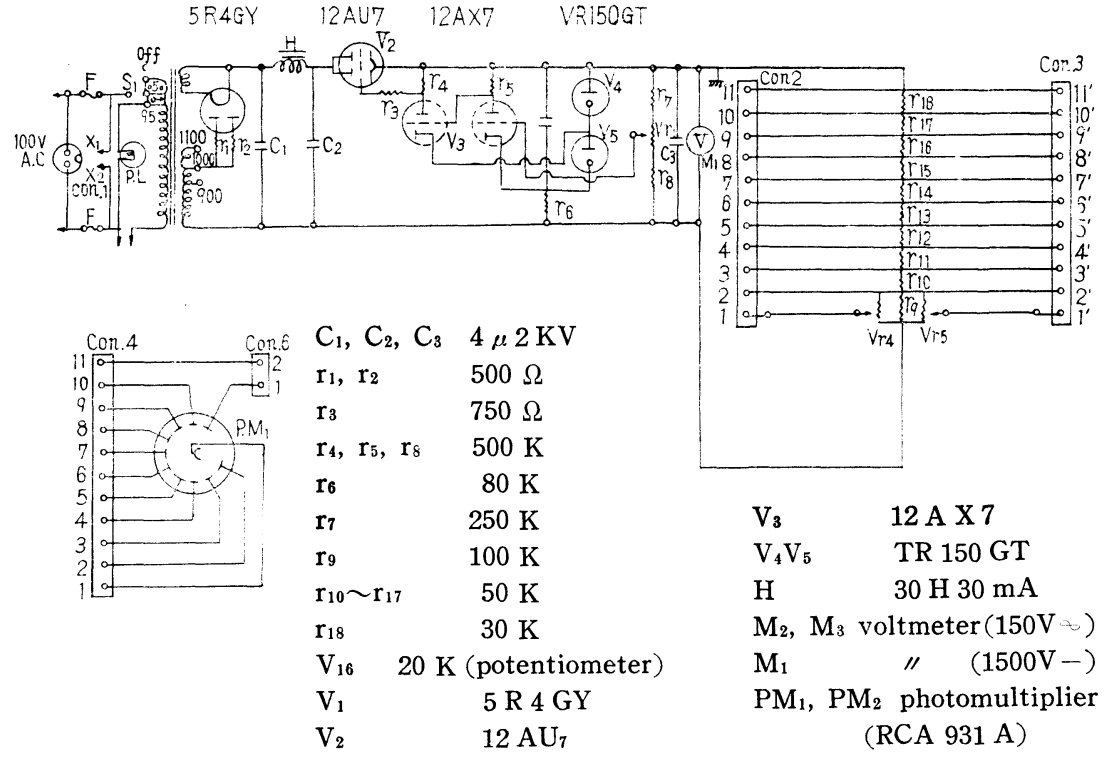

Fig. 3 Circuit of power source for photomultiplier
Roller $F_{2}$ is driven by synchronous motor $\mathrm{H}$. Rollers $F_{1}, F_{1}{ }^{\prime}$ and $F_{2}, F_{2}{ }^{\prime}$ are connected with gears. Rollers $F_{2}$ and $F_{2}{ }^{\prime}$ are wrapped in sand paper to avoid slippage between the roller and the specimen, which is carried at a speed of $1.5-4.5 \mathrm{~mm} / \mathrm{sec}$.

2-2 Optical System

Light passing through the slit and falling vertically on the cloth is reflected on two mirrors, $D_{1}, D_{2}$, and received by photoelectric cell $B_{1}$. The mirrors are placed on a plane parallel to the direction of the cloth movement and including the axis of incident light but in a direction oblique to incident light at an angle of $45^{\circ}$.

Penetrating light is received directly under the cloth by a photoelectric cell through milk-white glass and a slit.

A 150 -watt, $100 \mathrm{~V}$ projector bulb is used as the light source. Light is condensed through lenses $C_{5}, C_{6}$ and passeed through lens $C_{3}$ and slit $J_{1}$. On lens $C_{4}$ it becomes parallel light and runs to the cloth through the slit. The slit in the cloth is $0.8 \mathrm{~mm}$ wide and $15 \mathrm{~mm}$ long, the lengthwise side being at the right angle to the direction of cloth movement.

Intensity of the light source is varied by a trans. former, depending upon the type of cloth, to adjust the input current for the amplifier. The reason is that the absorption, reflection and penetration of light vary in amount with the color or the surface character of cloth.
To measure irregularity sensitively, the slit should be made as small in width as possible, although too narrow a slit makes measurement difficult. Therefore, we made the slit $0.8 \mathrm{~mm}$ wide. To obtain brighter reflection, a 150-watt tungsten lamp for projectors was used and its light condensed by a large condenser lens.

An RCA 931 A photomultiplier having a high amplification rate was used for the photoelectric cell. Paper was set in front of the photocell in order for incident light to be scattered more evenly on the sensing element of the tube.

\section{2-3 Electrical System}

Fig. 3 shows the circuit of the power source for the photomultiplier. A voltage-regulator tube VR 150 GT was used to reduce variations in anode voltage caused by variations in supply voltage. The electric stabilizer 4 shown in Fig. 1 was used to obtain a uniform input voltage. The output of photoelectric cell was amplified by a DC amplifier and recorded on a pen-recording oscillograph.

\section{2-4 Reproducibility of Apparatus}

To investigate the reproducibility of the measured curves, the specimens were sewn together, end to end, to form an endless belt. Two narrow strips of white paper were pasted parallel to the slit before and after the sewn line. The measured curves had good reproducibility, as shown in Fig. 4, and made deep valleys at the labeled places. 


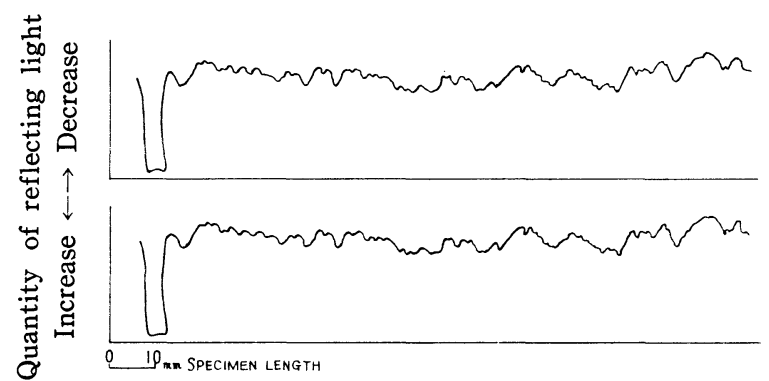

Fig. 4 Reproducibility of curve

\section{Method of Experimenting}

Table 1 lists the cloth specimens, their densities, materials of which made, yarn counts and cloth defects judged intuitively. The specimens were cut $4 \mathrm{~cm}$ in width and $65 \mathrm{~cm}$ in length, and carried endlessly by driving rollers at speeds of $1.5-4.5 \mathrm{~mm} / \mathrm{sec}$.

To evaluate the defects in the warp direction, the specimens had been made in such a way that the weft direction was taken as lengthwise. On the other hand, the warp direction was taken as lengthwise to measure the defects in the weft direction. Feed speed of chart was fixed at $5 \mathrm{~mm} / \mathrm{sec}$ or $15 \mathrm{~mm} / \mathrm{sec}$.

In the experiment on the relation between the degree of irregularity evaluated intuitively and the amplitude of experimental curves, we obtained the constant average value $(13 \mathrm{~mA})$ of the amplifier's output current by varying the light intensity, irrespective of the colors of the specimens. The gain of amplifier was fixed at a given value.

\section{Results of Experiments}

Schulze classified the streaks of cloth under two categories; (1) inner streaks traceable to uneven dyeing or the inherent luster of cloth; (2) outer streaks attributable to the irregularity of cloth structure, of surface contour or of yarn space.

Cloth defects may, likewise, be roughly divided into inner and outer. Inner defects are caused by the difference in fine structure between fibers making up the yarn of which cloth is made, or by the difference between the chemical and physical properties of the constituent fibers. Outer defects are due to irregularity in the arrangement and curvature of yarns. Similarly, the cloth defects listed in LO 208 of the Japan Industrial Standards (JIS) may be classified in

Table 2 Fabric Defects Classified

\begin{tabular}{l|l}
\hline Classification & \multicolumn{1}{|c}{ Fabric defects } \\
\hline \multirow{3}{*}{ Inner defects } & $\begin{array}{l}\text { Barré dyeing, Uneven bleaching } \\
\text { Uneven dyeing, Shiner }\end{array}$ \\
\hline \multirow{5}{*}{ Outer defects } & $\begin{array}{l}\text { Heavy filling bar, Light filling bar, } \\
\text { Hole defect, Stop mark, Float, Barré, } \\
\text { Filling bar by incorrect loom setting, } \\
\text { Wrong gating, Pirn sloughing, Fissure, } \\
\text { Crack, Core yarn cut, Filling skip, } \\
\text { Uneven crepe, Wrong weave, Warp } \\
\text { stripe, Warp falling, Tight warp, Slack } \\
\text { warp, Stripe defect, Unevenness of } \\
\text { weft, Tight pick, Slack pick, Twinkle } \\
\text { effect, Open-set mark, Pulled-in filling }\end{array}$ \\
\hline
\end{tabular}

Table 1 Fabric Specimens

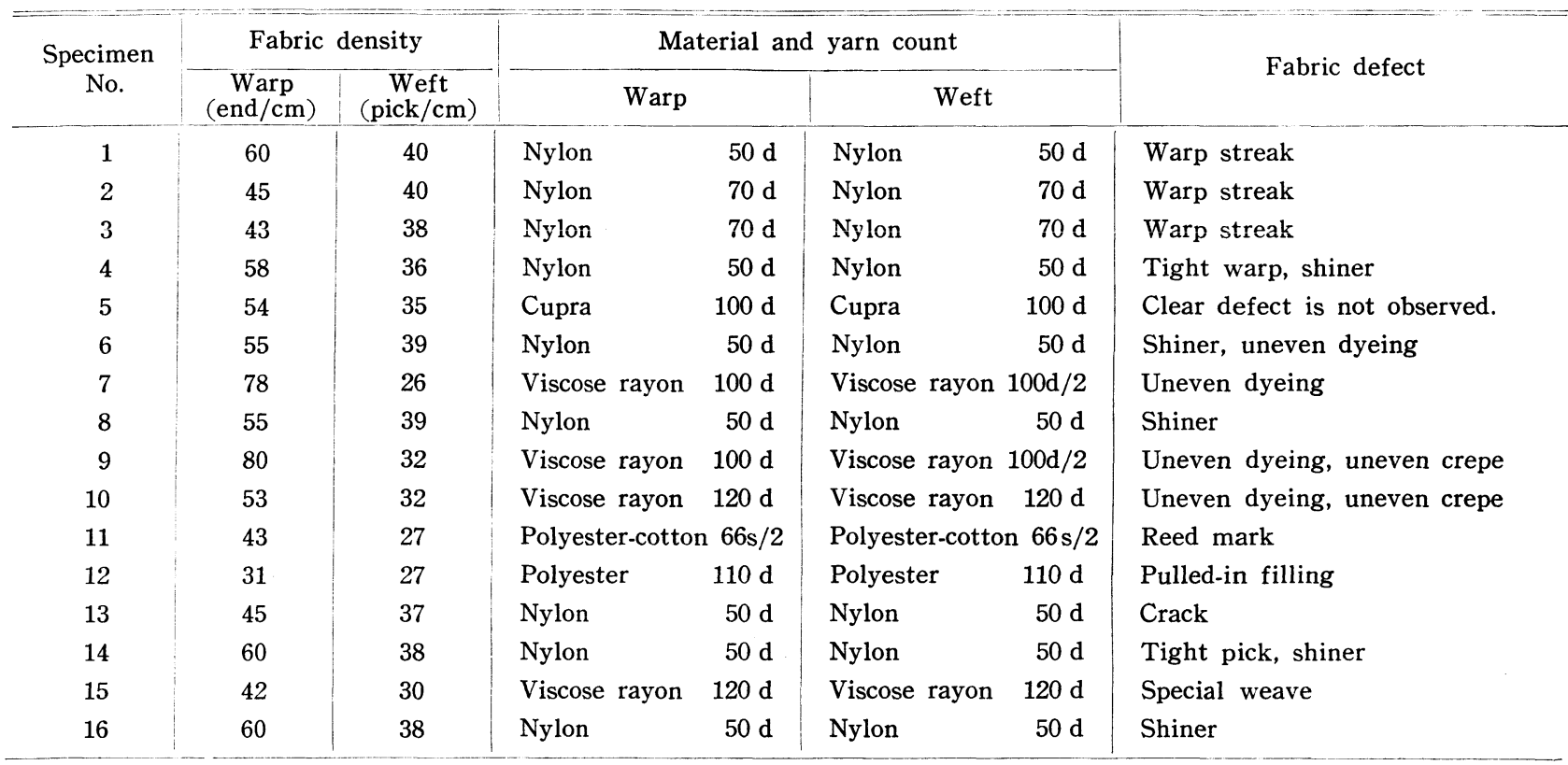


Table 2.

In some cases, only one of these defects shows up in a cloth. In others, many of them show up in a cloth at the same time. Specimens having inner or outer defects were observed in our experiment. Inner defects, it was believed, could be measured with reflecting light. It seemed hardly possible to measure them with penetrating light, unless there was remarkable uneveness in color shade.

It seemed difficult to detect outer defects by reflecting light - except defects traceable to irregularity in the yarn curvature on the plane vertical to the cloth surface, such as shiners and uneven crepe.

As for spun fabrics, unevenness of fabrics having reed marks or dyed patterns was undetectible by reflecting light, because those defects were traceable to the inherent irregularity of yarn thickness and hariness of the yarn.

Nor was yarn float or irregular structure in dense fabrics woven out of thick yarns measurable with penetrating light.

Cloth defects should be detected simultaniously by both reflecting and penetrating lights.

The results of experiments on some fabrics are explained in what follows.

(i) Measurement with reflecting light.

The appearances of specimens Nos. 7 and 16 and their reflection curves are shown in Fig. 5 . No. 7 had warp streaks due to cross dyeing effects arising from the difference in fiber properties. Therefore, the curve went slowly up and down in light-color shade areas.

No. 16 had two adjacent dull warp yarns woven periodically by sectional warping. The curve rose distinctly in dull-yarn areas. It seems possible, then, to measure inner defects with reflecting light, but not with penetrating light.
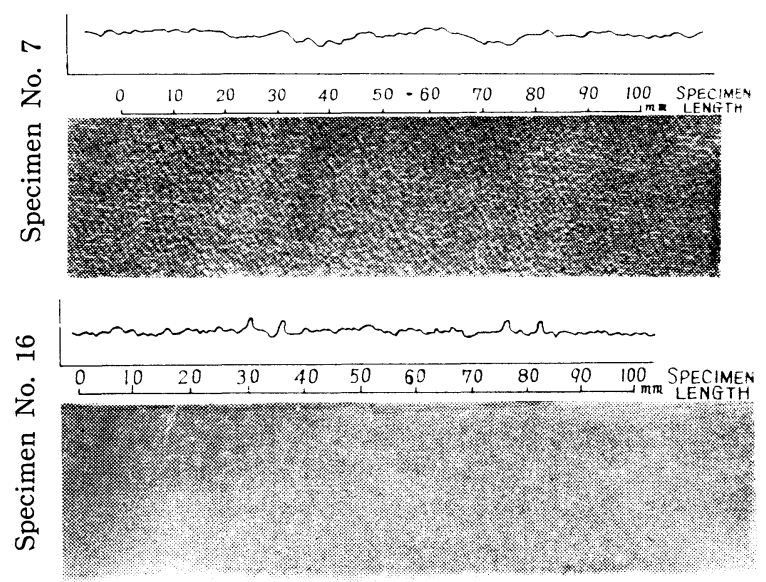

Fig. 5 Photos and light reflection curves of specimens
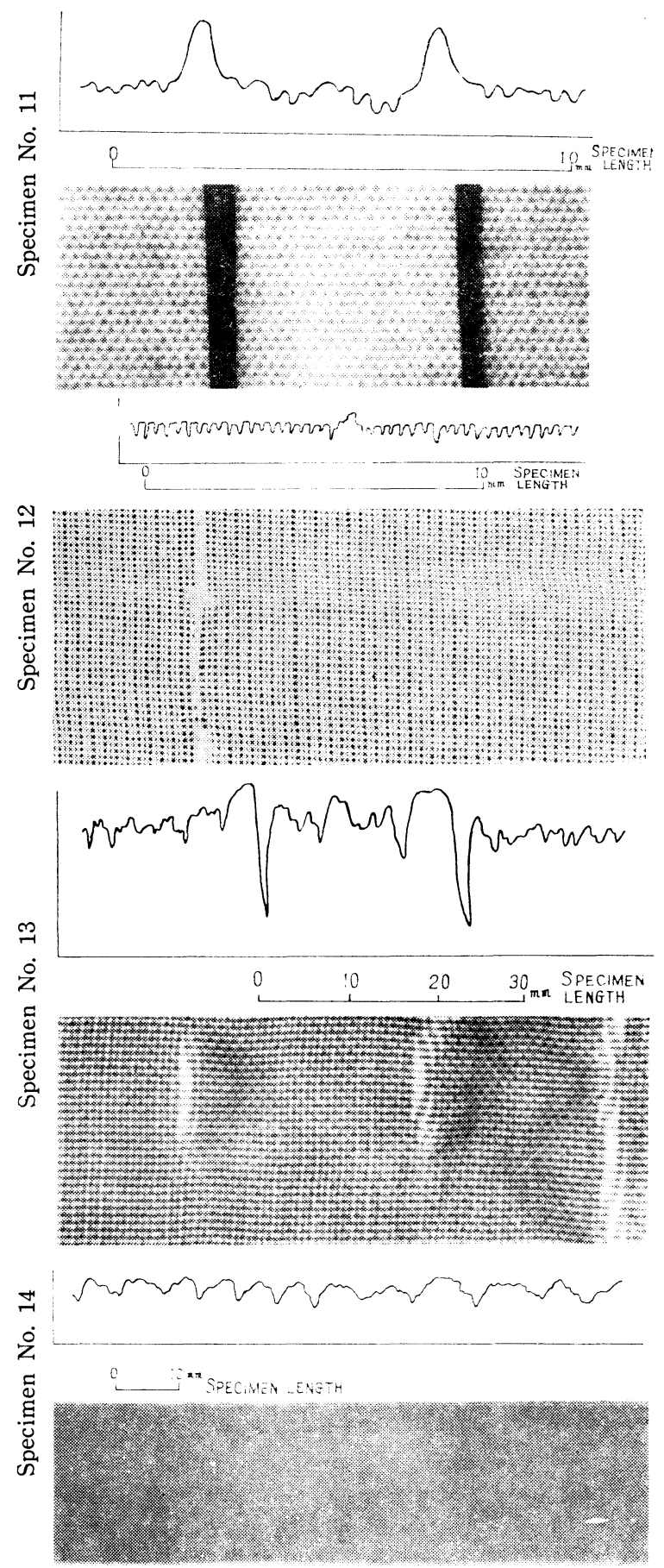

Fig. 6 Photos of specimens and curves of penetrating light

(ii) Measurement with penetrating light

Fig. 6 shows the appearances and irregularity curves of specimens Nos. 11, 12, 13 and 14. No. 11 had reed marks and their positions were indicated with black tapes stuck on the cloth. The curse rose distinctly in 
the tape-covered areas, because the tapes shut off the light. The curve went down at the reed marks because more light passed through the larger yarn spaces.

No. 14, having been woven under abnormally high tension, had tightpicks, with the curve varying periodically with the streaks produced by the irregularity of fabric thickness. These results show that outer defects can be detected by penetrating light.

(iii) Correlation between curves obtained by reflecting and penetrating lights.

The evidence so far shows that reflecting light can be used to measure inner defects and penetrating light to measure outer defects. Inner and outer factors together affect the cloth appearance at the same time in many cases. Therefore, irregularity curves were recorded at the same time for reflecting and penetrating lights for specimens Nos. 15, 1, 14, 6 and 7. Correlation coefficients were obtained from these curves and are shown in Table 3.

Fig. 7 shows irregularity curves. Fig. 8 is a photo of specimen No. 15 which was of a special weave with the yarn arrangement changing regularly. In a fabric like this, a correlation coefficient of a high value between two curves is obtainable, if there are no inner defects.

Table 3 Correlation between_Curves of Reflecting and Penetrating Lights

\begin{tabular}{r|c|c|c} 
Specimen No. & $\begin{array}{c}\text { Sample size } \\
\text { on curve }\end{array}$ & $\begin{array}{c}\text { Correlation } \\
\text { coefficient }\end{array}$ & $\begin{array}{c}\text { Significant } \\
\text { correlation } \\
\text { coefficient } \\
(\alpha=1 \%)\end{array}$ \\
\hline 15 & 100 & -0.824 & 0.256 \\
1 & 100 & -0.518 & 0.256 \\
14 & 100 & -0.488 & 0.256 \\
6 & 100 & -0.224 & 0.256 \\
7 & 100 & -0.160 & 0.256 \\
\hline
\end{tabular}
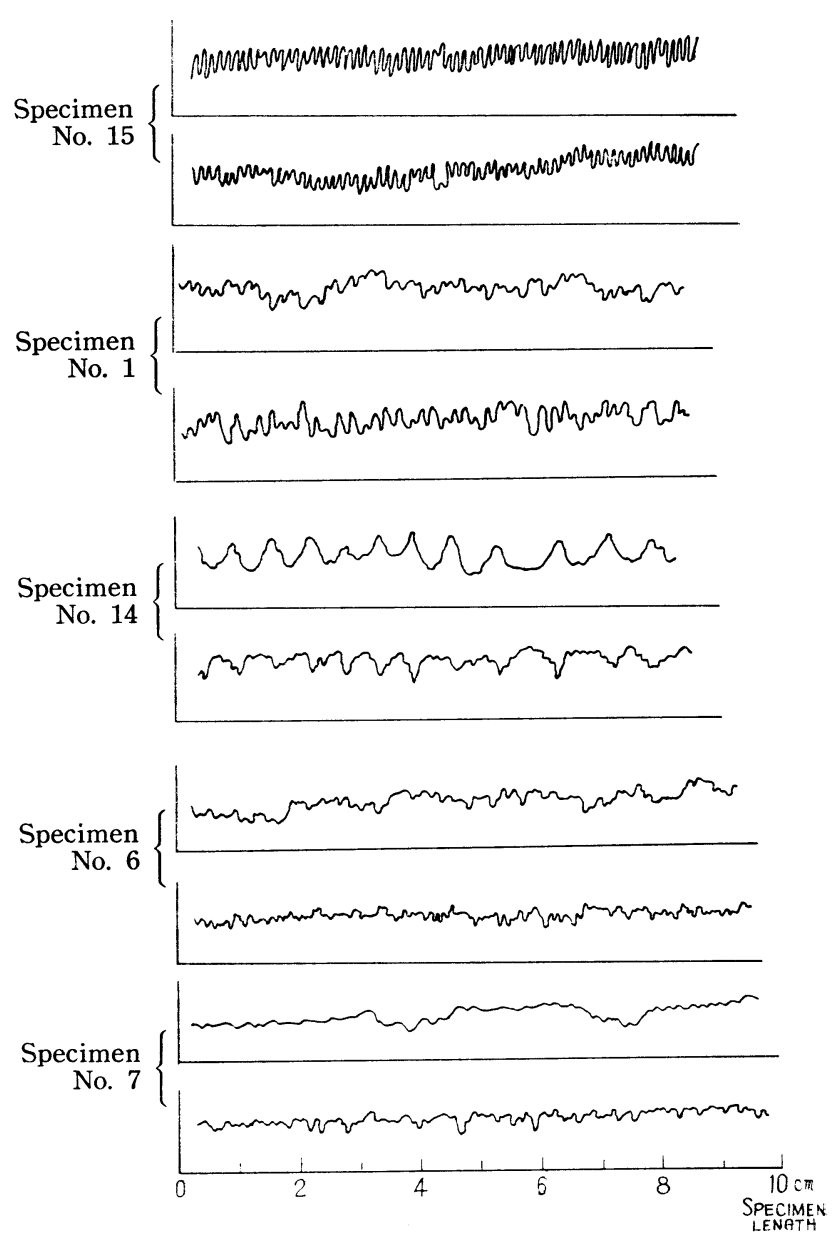

Fig. 7 Curves of reflecting and penetrating lights Top : Reflecting light Bottom : Penetrating light

Table 4 Standard Deviations (coded value) of Quantity of Reflecting Light

\begin{tabular}{|c|c|c|c|c|c|}
\hline \multirow{2}{*}{$\begin{array}{l}\text { Classification } \\
\text { Specimen No. }\end{array}$} & \multicolumn{2}{|c|}{ Non-crepe fabric } & \multicolumn{3}{|c|}{ Crepe fabric } \\
\hline & $\begin{array}{l}\text { Standard } \\
\text { deviation }\end{array}$ & $\begin{array}{l}\text { Intuitive } \\
\text { ranking }\end{array}$ & Specimen No. & $\begin{array}{l}\text { Standard } \\
\text { deviation }\end{array}$ & $\begin{array}{l}\text { Intuitive } \\
\text { ranking }\end{array}$ \\
\hline 1 & 1.854 & 1 & 6 & 2.044 & 1 \\
\hline 2 & 1.752 & 2 & 7 & 1.317 & 2 \\
\hline 3 & 1.626 & 3 & 8 & 1.107 & 3 \\
\hline 4 & 1.416 & 4 & 9 & 0.953 & 4 \\
\hline 5 & 0.951 & 5 & 10 & 0.716 & 5 \\
\hline $\begin{array}{l}\text { Coefficient of } \\
\text { ranking correlation } \\
\qquad\left(\boldsymbol{r}_{s}\right)\end{array}$ & \multicolumn{2}{|c|}{1.000} & $\begin{array}{l}\text { Coefficient of } \\
\text { ranking correlation } \\
\qquad\left(\boldsymbol{r}_{s}\right)\end{array}$ & \multicolumn{2}{|c|}{1.000} \\
\hline $\begin{array}{l}\text { Significant rank } \\
\text { correlation coeff. } \\
\qquad(\alpha=5 \%)\end{array}$ & \multicolumn{2}{|c|}{0.900} & $\begin{array}{l}\text { Significant rank } \\
\text { correlation coeff. } \\
\qquad(\alpha=5 \%)\end{array}$ & \multicolumn{2}{|c|}{0.900} \\
\hline
\end{tabular}




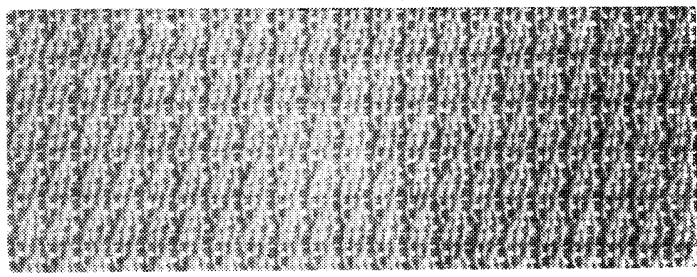

Fig. 8 Photo of specimen No. 15

Specimen No. 1 had an uneven warp arrangement and a shiner. The correlation coefficient in this specimen was also considerably large, though not as large as in No. 15.

Specimen No. 14 exhibited both irregularity of density and a shiner produced by tight filling. Its correlation coefficient was smaller than in No. 1, because there were more inner defects than outer in the specimen.

Specimens Nos. 6 and 7 had inner defects, such as uneven dyeing and shiners, but few outer defects. Therefore, hardly any correlation was observable between two curves. This, then, means that the correlation between two curves obtained for reflecting and penetrating lights is significantly large if there are many outer defects - and very small if there are many inner defects.

(iv) Relation between irregularity curves and evaluation. by perception

The amplitudes of irregularity curves at the same output level and irregularity evaluated by perception have been compared by obtaining the standard deviations of curves shown in Table 4. Data obtained from visual evaluations of the same fabrics by five persons are given in Table 5 . The rankings of the visual observations agree well with each other by Kendall's concordance test at $5 \%$ significance level. The

Table 5 Ranking of Fabric Defects Intuitively Evaluated

\begin{tabular}{|c|c|c|c|c|c|c|c|c|c|c|c|}
\hline $\begin{array}{r}\text { Specimen } \\
\text { No. } \\
\text { Evaluator }\end{array}$ & 1 & 2 & 3 & 4 & 5 & $\mid \begin{array}{r}\text { Specimen } \\
\text { No. } \\
\text { Evaluator }\end{array}$ & 1 & 2 & 3 & 4 & 5 \\
\hline A & 1 & 3 & 2 & 4 & 5 & $\mathrm{~A}$ & 1 & 2 & 3 & 3 & 3 \\
\hline B & 1 & 2 & 3 & 4 & 5 & B & 1 & 2 & 4 & 3 & 5 \\
\hline $\mathrm{C}$ & 1 & 2 & 3 & 3 & 5 & $\mathrm{C}$ & 1 & 2 & 3 & 3 & 3 \\
\hline D & 1 & 2 & 3 & 4 & 5 & $\mathrm{D}$ & 1 & 2 & 3 & 4 & 5 \\
\hline $\mathrm{E}$ & 1 & 3 & 2 & 4 & 5 & $\mathrm{E}$ & 1 & 2 & 3 & 4 & 5 \\
\hline $\mathrm{W}^{*}$ & \multicolumn{5}{|c|}{0.915} & $\mathrm{~W}^{*}$ & \multicolumn{5}{|c|}{0.635} \\
\hline F & \multicolumn{5}{|c|}{43.06} & F & \multicolumn{5}{|c|}{6.96} \\
\hline $\mathrm{F}_{\alpha} * *$ & \multicolumn{5}{|c|}{3.6} & $\mathrm{~F}_{\alpha} * *$ & \multicolumn{5}{|c|}{3.6} \\
\hline
\end{tabular}

* Kendall's concordance coefficient

** Significant value of $\mathrm{F}(\alpha=5 \%)$

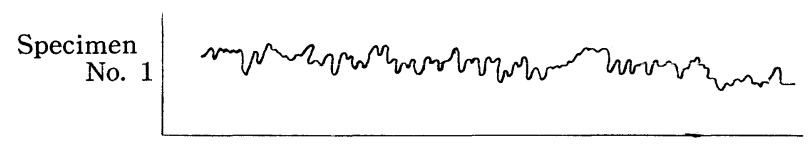

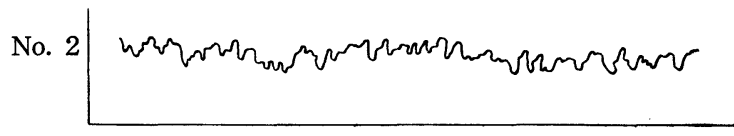
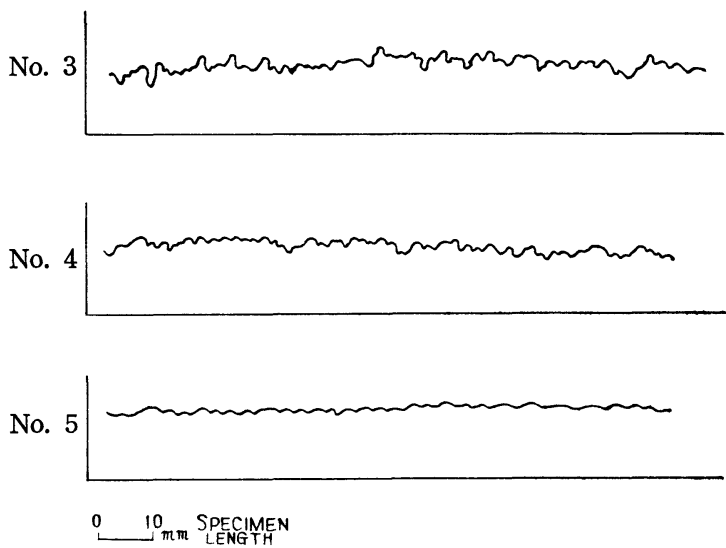

Fig. 9 Curves of light reflecting on specimens Nos. $1 \sim 5$
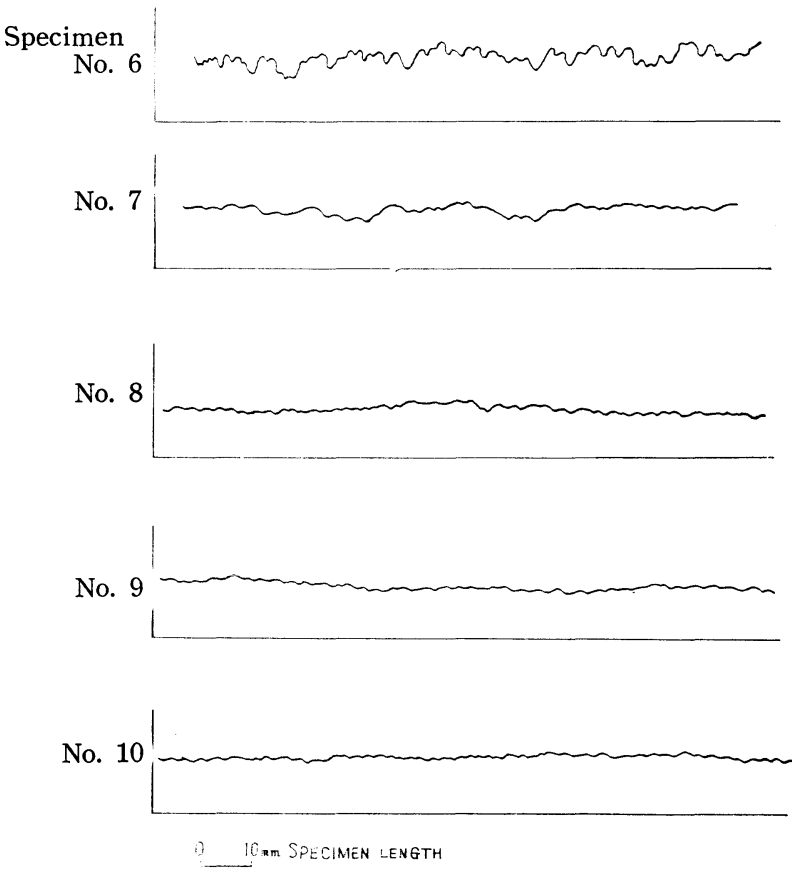

Fig 10 Curves of light reflecting on specimens No.s. $6 \sim 10$

ranking coincides also with the ranking of standard deviations obtained from the irregularity curves given in Table 4. Irregularity curves are arranged in the same order in Figs. 9 and 10 as in Table 5. 


\section{Discussion}

Measurement with reflecting light is good only for unpatterned fabrics, but not for fabrics having woven or dyed patterns. Penetrating light cannot detect defects in thick or dense cloth. Cloth defects are easily detectible when light for measuring changes more sharply than the average level of observed values.

It is very difficult to detect defects when observed light changes slowly in quantity even if the quantity of the light is considerably large in absolute value. To measure the cloth defect continuously and automatically by this method, the whole width of cloth must be looked over. It takes a recording apparatus like Uster's Imperfection Indicator to find out the number of impulses exceeding a given range on both sides of the average value of irregularity curves caused by reflecting or penetrating light. How to fix the range is another question.

\section{Summing up}

Cloth defects were measured optically by casting light on a running cloth and by observing continuously and recording automatically light reflecting on the cloth and light penetrating it.

The results of the experiments are :

(i) A cross-dyed effect, shiners, etc. are exactly measurable by reflecting light. These defects are presumably caused by the difference in fine structure between the physical and chemical properties of fibers.

(ii) Reed marks, cracks, filling bars, etc. are accurately measurable by denetrating light. These defects are attributable to differences in yarn arrangement or yarn curvature caused mainly by poor preparations and weaving processes.

(iii) Either reflecting or penetrating light can measure inner defects, such as cross-dyed effects of a noticeable shade difference; and outer defects, such as irregularity of cloth woven out of continuous filament yarns or irregularity of thin cloth woven out of spun yarns. Inner defects are accurately caught by reflecting light, rather than by penetrating light.

(iv) The correlation between curves obtained by reflecting and penetrating lights is large for cloth containing outer defects, and is small for cloth having inner defects.

(v) Standard deviations of curves are obtained at the same level of reflection. The larger the number of defects intuitively evaluated, the larger the value of standard deviations. The subjective ranking of cloth agreed well with that of these standard deviations.

\section{References :}

[1] H. Catling ; J. Text. Inst., 49, T232 (1958-5)

[2] F. Schulze ; Mod. Text. Mag., 39, 69-89 (1958-12)

[3] General Assembly, Bull. Inst. Text. France, 95 (1957-8)

[4] N. Bigler ; S.V.F., 652 (1955-12)

[5] W. Fester, P. Küppers ; Textil-Praxis, 342 (1965-4) 